\title{
Theory of Mind in Evaluating Pain Symptoms
}

\author{
Preston A Long and XT Wang* \\ Department of Psychology, University of South Dakota, USA
}

Submission: May 24, 2017; Published: May 31, 2017

*Corresponding author: Xiao-Tian Wang, Department of Psychology, University of South Dakota, 414 East Clark Street, Vermillion, SD 57069, USA, Email: xtwang@usd.edu

\begin{abstract}
Accurate evaluation of pain based on subjective information of the patients has always been a challenge for medical professionals. The primary pain evaluation methods based on subjective measurements are vulnerable to manipulation and deception. This may be particularly problematic if the patient is knowledgeable about the assessed symptomology. In this preliminary study, we examined the theory of mind of ordinary people in evaluating pain symptoms presented in hypothetical scenarios that varied in the level of knowledge of the patient about pain symptoms (health care professional vs., lay person), Intentional Bias (understatement vs. exaggeration) and the moral basis of the intention (selfish vs. altruistic). The results showed a significant effect of intention of the pain patient, where an intent to exaggerate was judged to be more difficult to fake than understating the pain symptoms. This result suggests that theory of mind operates on detecting specific intention of the target person more than the cognitive capacity or morality of the person
\end{abstract}

Keywords: Theory of mind; Deception; Pain evaluation

\section{Introduction}

Physical pain is highly subjective. Evaluation of pain symptoms, as well as the proposed methods for its improvement, has long been debated. This dilemmais only compounded by and therefore is usually separated from, the fact that pain assessments can be easily manipulated by the patient. The problem has become increasingly apparent as prescription pain killer abuse continues to mount. A meta-analysis reviewing six studies using standardized patients (actors) and real patients found that even when doctors were aware of the chance for deception, it was correctly detected only ten present of the time [1]. However, several related questions are rarely addressed. How do people assess pain symptoms reported by others with different intentions? Would people generally trust a healthcare professional more or less than a lay person in terms of reported pain symptoms? The layman can bias his assessment if so motivated, without insight of the metrics used. A healthcare practitioner then might be more masterful at the misrepresentation of his or her pain. Some studies suggest that the effectiveness at deception can be enhanced by a person's extent of pertinent knowledge [2].

Practically, these issues rise from either a concern of selfish motive to fake symptoms or a concern of altruistic motive to continue to work. The issue of evaluating subjective pain symptoms also involves healthcare practitioners as patients. The term healthcare practitioner is applied broadly to medical professionals that provide direct services to patients, primarily, physician assistants, medical doctors, surgeons, and nurses. Healthcare practitioners work in a culture of self-sacrifice. There may be a disposition among healthcare practitioners to put themselves at risk for the benefit of the patients. This sacrifice can come in the form of overworking, working while injured and misrepresenting degrees of injury. Although the intent can be beneficence, there are often unforeseen consequences. A practitioner may provide suboptimal service if distracted by pain [3]. There is also the potential for further injury resulting in a longer disruption in the continuity of service practitioners strive to provide.

So, when the practitioner is on the other side of the clipboard, how do we assess their pain? How difficult will an accurate assessment be? Will such judgement be dependent on the knowledge level about pain or detected intention to exaggerate or understate the pain, or the Moral reasons (selfish or altruistic) behind the intention? We propose that when making such assessment about reported pain symptoms, the input information will activate a theory of mind in reviewers. Theory of mind has been an increasingly popular topic in social, 
cognitive, and developmental psychology over the past couple decades. This area of research investigates the human capacity to predict one another's causal behavior and mental states, including feelings, perceptions, emotional states, beliefs, desires, intentions, and hopes [4].

For a simple example, imagine the following scenario: Christian was cleaning his room and threw away a handful of papers. Amongst these papers was a homework assignment due the following day. While out playing, Christian's mother emptied his trash bin into the primary receptacle. When Christian becomes aware that his assignment was among the trash discarded, what will he do upon his return? Christian does not know that his mother emptied the garbage in his room, and falsely believes it remains in the bin. The obvious answer is he will check the bin in his room first, and be anxious to find it empty. Correctly answering this question regarding false belief demonstrates one's theory of mind [5]. It requires an assumed understanding of what someone else thinks, what knowledge they have, and what behaviors will result from it. This ability is not unique to human beings; chimpanzees also demonstrate such capacity [6]. In normal children, the onset of a theory of mind around the age of two or three parallels with their ability to lie [7]. The capacity for deception is not innate, it must develop. In fact, our natural state is truth-telling. When an individual tells the truth, there is no activation in the brain beyond that of speech. However, deception engages particular additional areas of the brain [8]. Furthermore, it is our nature to have a truthdefault (assumption of honesty) when listening to others [9].

For this study, a unique application of theory of mind is applied. A primary objective is to evaluate how difficult it is for a participant to obtain an accurate pain assessment via a theory of mind. We examined the theory of mind of ordinary people in evaluating pain symptoms presented in hypothetical scenarios that varied in the level of knowledge of the patient about pain symptoms (health care professional vs., lay person), Intentional Bias (understatement vs. exaggeration) and the moral basis of the intention (selfish vs. altruistic). A second exploratory objective was to better understand what types of evaluation methods are considered to be less prone to bias. The current gold standards are fraught with inaccuracy even when the patient is not attempting to mislead their pain level. Research shows a significant but small correlation between the nurses' and patients' pain ratings [10]. However, it is still more appropriate to use some form of assessment over verbal interaction alone. One study found that doctors using only informal interviews assessed their patient's pain at only chance levels compared to a seventy percent success rate from doctors using a standardized checklist evaluation [11]. In this study, instead of examining susceptibility to deception of specific tools provided, we compare several input factors in terms of their effects to activate theory of mind judgment. This approach would provide insights into what general methods are believed to be harder to manipulate.

\section{Hypothesis}

When evaluating pain symptoms people use their theory of mind to determine the accuracy of the reported pain based on the desire of the reporters to mispresent information and how much knowledge the reporter has about pain symptomology. In particular, we predict that levels of pain, motivation to exaggerate or understate, and knowledge level about pain symptoms independently or jointly affect assessment of the pain by a reviewer. It would feel more difficult for a participant to judge the accuracy of pain symptoms reported by healthcare than a non-healthcare professional when a motive is detected.

\section{Methodology}

Participants: Twenty-eight junior and senior undergraduate university students participated in the study. No identifying information was collected including age, gender, and ethnicity. The participants were first engaged in a self-study training session. They were given four different pain scale questionnaires to study how to evaluate pain symptoms. They were instructed to spend about ten minutes familiarizing themselves with the scales before reviewing the scenarios. The four scales chosen to help the participants to evaluate pain symptoms include The McGill Pain Questionnaire [12], the Pain Quality Assessment Scale [13], the Dallas Pain Questionnaire [14], and the Örebro Musculoskeletal Screening Questionnaire [15]. These scales provided the participants with symptomology checklist and numerical/visual scaling. Note that the participants did not complete or attempt to score any of the assessments. They were provided as training tools for the purpose of evaluating pain symptoms.

Following the training session, each participant was provided with a packet containing eight vignettes, sorted in a random order. For each vignette, they were asked to answer the following questions: What questions would you ask the patient to discover their true pain level? Which pain scale provided would you most likely use in this case, if, you are most concerned with patient bias? For the purpose of the present study, the key question for analysis was about the subjective estimate of the accuracy the pain assessment: How accurate of pain measurement do you believe you could achieve? A five-point Likert-type scale was provided to assess the degree of accuracy (1= not accurate, 5=highly accurate).

Experimental Design: We adopted a within-subject 2 by 2 by 2 factorial design. The three variables manipulated in the scenarios include knowledge level of the hypothetical pain patient (healthcare practitioner vs. lay person), the patient's Intentional Bias in reporting pain symptoms (understatement vs. exaggeration), and Moral reasons behind the intention (selfish vs. altruistic/benevolent).The knowledge level was manipulated via the occupation of each of the characters in a scenario: healthcare practitioner or non-practitioner (lay person). The specific titles named in the vignettes for the healthcare practitioner were 
nurse, surgeon, physical therapist, and medical doctor. The nonpractitioner occupations were most often physically active jobs such as boxer and construction foreman. Intentional Bias was implemented via the description of the intention of the patient to either understate or overstate the pain levels. The exaggerating patients desired their pain levels to be assessed as higher than in reality, whereas the understated patients attempted to receive lower assessments of pain than was felt. Moral reasons behind the intention were either selfish or altruistic/benevolent. The altruistic motives include not wanting to abandon patients as a result of an injury. The selfish motives included not wanting to fall behind in a race for promotion. It is worth noting that the field of sociology has long claimed that there is no such thing as true altruism and that in fact all acts are egotistic. However, research conducted on the empathy-altruism hypothesis has shown that some acts can be utterly for the benefit of another [16]. This is particularly relevant to the culture of self-sacrifice observed in health care.

Vignettes: The within-subject 2 by 2 by 2 factorial design was implemented with eight vignettes and were provided to establish a theory of mind test for the participants. The vignettes contain a short story of a character who was injured and is currently under evaluation of their pain. How they were injured, their occupation, why they wish to mislead the evaluator and how they want their pain level to be perceived was presented. The language used to describe the intensity was consistent. The participants were instructed to imagine they were the practitioner assessing the character's pain level. Each vignette has alternating combinations of the three variables.

The following example was one of the eight scenarios with a practitioner, understated pain symptoms, and benevolent motive combination. A surgeon performed a ten-hour surgery which requires an awkward posture to complete. In the final thirty minutes, the surgeon felt a distinctive twinge in his lower back. The resulting pain was so distracting that the surgeon's work was significantly impaired. However, the surgeon is scheduled to perform a novel surgery procedure the following day which could make his career. As a result, he understated his pain level.

\section{Results}

To examine a theory of mind's effect on predicted painassessment accuracy scores a one-way repeated measures ANOVA was performed. The independent variables (conditions) were knowledge level (healthcare practitioner vs. nonpractitioner), Intentional Bias (understated pain vs. exaggerated pain) and moral reason (altruistic motivation vs. selfish motivation). The overall $\mathrm{F}$ for differences in perceived accuracy scores across conditions was significant: $F(5,23)=4.051$, $\mathrm{p}=.009 ; \eta_{\mathrm{p}}{ }^{2}=0.468$. This suggests that when controlling for individual differences approximately $47 \%$ of the variance in predicted assessment accuracy scores was accounted for by the three theory of mind variables manipulated in the scenarios. Paired samples t-tests were performed to compare scores between each of the opposing paired variables to help explain the significance. Results only showed one significant difference in predicted accuracy of Intentional Bias between understate $(\mathrm{M}=3.32, \mathrm{SD}=.81)$ and exaggerate $(\mathrm{M}=3.12, \mathrm{SD}=.79) ; \mathrm{t}(83)=$ $2.4, \mathrm{p} .=.019$. The participants believed that it was easier to detect understatement of pain symptoms than exaggerating the symptoms.

Pair wise comparisons were also conducted to evaluate the differences amongst complete vignettes which contain mixed combinations of the theory of mind variables. The NonPractitioner/Selfish/Exaggerated $(\mathrm{M}=2.89, \mathrm{SD}=.72)$ condition was predicted by the participants as more difficult (less accurate) to detect deception than other combinations with the exception of Practitioner/Selfish/Exaggerated ( $M=3.1, S D=.72)$. The combination of Non-Practitioner/Selfish/Understated were viewed by the participants as easiest to detect with the highest mean score of predicted assessment accuracy ( $M=3.42$, $\mathrm{SD}=.62$ ). Likely as a result of the small $\mathrm{n}$ and the lack of medical knowledge of the sample, no significant results were discovered concerning the assessment types. The recommended metrics for each scenario were inconsistent, and few if any follow-up questions were suggested. However, while still not statistically significant, there was an observable trend preferring the use of open-ended questions over checklist or scale based modalities.

\section{Discussion}

Among the factors manipulated in this study motivation to overstate or understate pain symptoms significantly affected assessment of the reviewers (the participants). This result showed that the intention is a key input for a theory of mind calculation more so than the level of knowledge about pain symptoms. The ability of detect the intention of others is a developmental milestone in early childhood development. While normally developing children had a $50 \%$ chance of passing false belief tasks at age of 4 years, children with autism often fail theory of mind tasks $[17,18]$. Anassumption of theory of mind might be that everyone including children can lie and may be equally good at it, despite significant differences in knowledge levels among them.

One of the aims of this study was to demonstrate that people would perceive a healthcare practitioner actively attempting to misrepresent their pain levels as more difficult to see through than people with different backgrounds doing the same. This idea was not supported by the results. One potential explanation for this is that society considers practitioners to be an ethics based practice. Healthcare practitioners are regarded as trustworthy on a societal level. So even when being told the practitioner is lying, the participants might assume that healthcare workers would mitigate their lies in comparison to other professions. 
There is also evidence suggesting that a person has more inaccuracy in cheater detection if the individual they evaluate is in a higher social status [19].

Furthermore, the results suggest that a theory of mind view of symptom evaluation is intention-dependent. The mechanisms at play to exaggerate one's pain compared to understating it may be distinct. To overstate pain, some acting skills are required. A person must pretend something is present when in fact it is not. This is relatively easy to accomplish and difficult to perceive. However, to understate pain self-control is required. A person must pretend something that is in fact there is not. An afflicted person must hide their pain in smiles and normal ranges of motion. This process may be less practiced in our everyday lives and tends to be more noticeable. Also, the faking of pain does not necessarily require any professional knowledge. Children practice this skill at an early age to avoid school. Pain symptoms are understood and are quite common for everyone.

\section{Conclusion}

This preliminary study was focused on how ordinary people exercise their theory of mind to evaluate reported pain symptoms. Future studies should also include actual healthcare practitioners as participants to examine how healthcare professionals evaluate each other's intention and reported symptoms.

\section{References}

1. Jung B, Reidenberg MM (2007) Physicians being deceived. Pain Med 8(5): 433-437.

2. Lanyon RI (1997) Detecting deception: Current models and directions. Clinical Psychology: Science and Practice 4(4): 377-387.

3. Wallace JE, Lemaire JB, Ghali WA (2009) Physician wellness: a missing quality indicator. Lance 374(9702): 1714-1721.

4. Goldman AI (2012) Theory of mind. The Oxford Handbook of Philosophy of Cognitive Science, Oxford University Press, India, pp. 402-424.

5. Frith C, Frith U (2005) Theory of mind. Current Biology 15(17): R644-R645.
6. Premack D, Woodruff G (1978) Does the chimpanzee have a theory of mind? Behavioral and brain sciences 1(4): 515-526.

7. Ding XP, Wellman HM, Wang Y, Fu G, Lee K (2015) Theory-of-mind training causes honest young children to lie. Psychol Sci 26(11): 18121821.

8. Spence SA, Hunter MD, Farrow TF, Green RD, Leung DH, et al. (2004) A cognitive neurobiological account of deception: evidence from functional neuroimaging. Philos Trans R Soc Lond B Biol Sci 359(1451): $1755-1762$.

9. Levine TR (2014) Truth-Default Theory (TDT): A theory of human deception and deception detection. Journal of Language and Social Psychology 33(4): 378-392.

10. Choinière M, Melzack R, Girard N, Rondeau J, Paquin MJ (1990) Comparisons between patients' and nurses' assessment of pain and medication efficacy in severe burn injuries. Pain 40(2): 143-152.

11. Akehurst L, Easton S, Fuller E, Drane G, Kuzmin K, et al. (2017) An evaluation of a new tool to aid judgements of credibility in the medicolegal setting. Legal andCriminological Psychology 22(1): 22-46.

12. Melzack R, Katz J (2001) The McGill Pain Questionnaire: Appraisal and current status. Guilford Press, USA.

13. Jensen MP, Gammaitoni AR, Olaleye DO, Oleka N, Nalamachu SR, et al. (2006) The pain quality assessment scale: assessment of pain quality in carpal tunnel syndrome. J Pain 7(11): 823-832.

14. Lawlis GF, Cuencas R, Selby D, McCoy CE (1989) The Development of the Dallas Pain Questionnaire: An Assessment of the Impact of Spinal Pain on Behavior. Spine 14(5): 511-516.

15. Linton SJ, Boersma K (2003) Early identification of patients at risk of developing a persistent back problem: the predictive validity of the Örebro Musculoskeletal Pain Questionnaire. Clin J Pain 19(2): 80-86.

16. Batson CD, Shaw LL (1991) Evidence for altruism: Toward a pluralism of prosocial motives. Psychological inquiry 2(2): 107-122.

17. Baron-Cohen S, Leslie AM, Frith U (1985) Does the autistic child have a "theory of mind"? Cognition 21(1): 37-46.

18. Happe FG (1995) The role of age and verbal ability in the theory of mind task performance of subjects with autism. Child Dev 66(3): 843855.

19. Cummins DD (1999) Cheater detection is modified by social rank: The impact of dominance on the evolution of cognitive functions. Evolution and Human Behavior 20(4): 229-248.

Your next submission with Juniper Publishers
will reach you the below assets
- Quality Editorial service
- Swift Peer Review
- Reprints availability
- E-prints Service
- Manuscript Podcast for convenient understanding
- Global attainment for your research
- Manuscript accessibility in different formats
( Pdf, E-pub, Full Text, Audio)
- Unceasing customer service
Track the below URL for one-step submission
https://juniperpublishers.com/online-submission.php

